\title{
Provocative diskography: safety and predictive value in the outcome of spinal fusion or pain intervention for chronic low-back pain
}

This article was published in the following Dove Press journal: Journal of Pain Research

2 December 2014

Number of times this article has been viewed

\section{Paul CWillems \\ Department of Orthopedic Surgery, CAPHRI Research School, Maastricht University Medical Center, Maastricht, the Netherlands}

\begin{abstract}
There is still no clear definition of diskogenic low-back pain and no consensus on a generally agreed test, such as provocative diskography (PD), to diagnose painful disk degeneration, and probably more importantly, to predict the outcome of therapy intended to reduce pain that is presumed to be diskogenic in nature. Nevertheless, PD is the most specific procedure to diagnose diskogenic low-back pain. Its accuracy, however, is rather low or at best unknown. Although rare, the most prevalent complication, postdiskography diskitis, can be devastating for the individual patient, so all measures, like strict sterile conditions and antibiotic prophylaxis, should be taken to avoid this complication. It is advised to perform the procedure in a pressurecontrolled way with a constant low flow, and optionally computed tomography imaging. PD should not be performed in morphologically normal disks. A standardized execution of the test should be established in order to perform high-quality studies to determine its accuracy to lead to meaningful interventions, and find best practices for diagnosis and treatment of diskogenic back pain. Possibly, PD may have detrimental effects on the disk, causing early degeneration, although it is unknown whether this will be related to clinical symptoms. Especially with these possible adverse side effects in mind, the risk-benefit ratio with the lack of clear benefits from treatments provided, and possible complications of disk puncture, the rationale for PD is questionable, which should be stressed to patients in the process of shared decision making. Diskography as a stand-alone test is not recommended in clinical decision making for patients with chronic low-back pain.
\end{abstract}

Keywords: provocative diskography, chronic low-back pain, prognostic accuracy, spinal fusion, pain intervention

\section{Introduction}

Chronic low-back pain (CLBP) is a major health problem in modern society, with lifetime prevalence up to $84 \% .^{1}$ The economic burden of low-back pain (LBP) is huge, and consists of direct costs of health care utilization (hospitalization, medication, tests, and therapies) and indirect costs of lost productivity due to work absenteeism and early retirement. In a small Western European country, such as the Netherlands, the total annual costs of back pain were estimated at $€ 4.4$ billion $^{2}$ (mainly employment-related costs). ${ }^{3}$ The total annual costs in the US have exceeded $\$ 100$ billion. $^{4}$

Roughly, LBP can be categorized ${ }^{5}$ as pain caused by spinal pathology, such as tumors, infection, trauma, nerve root or radicular pain, and a large heterogeneous group of patients (about $85 \%$ of total cases $^{6}$ ) suffering from LBP in whom imaging reveals signs of degeneration of one or more intervertebral disks (disk-space narrowing, vertebral end-plate changes, ${ }^{7,8}$ annular disruption,,${ }^{9,10}$ and/or facet joint arthropathy). These degenerative findings can also be observed in asymptomatic subjects, ${ }^{11}$ and thus
Correspondence: Paul C Willems Department of Orthopedic Surgery, CAPHRI Research School, Maastricht University Medical Center, PO Box 5800, Maastricht $6202 \mathrm{AZ}$, the Netherlands Tel +3l 433875038

Email p.willems@mumc.nl 
this last category of patients is often mentioned as suffering from CLBP.

CLBP has a substantial impact on the lifestyle of those affected, and several socioeconomic risk factors have been identified. ${ }^{12,13}$ Job dissatisfaction, low education, strenuous work, and workers' compensation insurance are all associated with CLBP and resulting disability. ${ }^{14,15}$ In addition, factors such as smoking, obesity, psychological distress, depressive mood, and to a lesser extent somatization, have been reported to result in increased risk of chronicity. ${ }^{16}$

\section{Rationale for invasive treatment of CLBP}

Intervertebral disk degeneration is considered to be the main cause of CLBP. The etiology and pathophysiology of disk degeneration, however, is unknown. Genetic predisposition may play an important role. ${ }^{17-19}$ Histologically, an abnormal ingrowth of sensory nerve fibers in the end plates and the nucleus pulposus has been observed. ${ }^{20}$ Radial fissures in the annulus fibrosus have been linked to the ingrowth of free nerve endings (nociceptors) and blood vessels with a granulation zone. ${ }^{21}$ Additionally, degenerative herniated disks contain high levels of proinflammatory mediators and cytokines, ${ }^{22,23} \mathrm{eg}$, interleukin 6 , nitric oxide, prostaglandin $\mathrm{E}_{2},{ }^{24}$ and phospholipase $\mathrm{A}_{2}{ }^{25}$

These findings have led to the idea that disk degeneration, with or without secondary osteoarthritis of the synovial facet joints, is a major source of pain in CLBP, which has led to minimally invasive interventional treatment of the disk to relieve pain. As the pain appears to be largely associated with continued motion and loading of the affected disk level, the idea has emerged of treating a painful degenerative-motion segment by spinal fixation and fusion.

First described in 1889 for stabilization of vertebral segments in spinal tuberculosis, ${ }^{26}$ spinal fusion is a successful treatment for fractures and deformity of the spine. Spinal fusion for CLBP, however, remains controversial. ${ }^{27,28}$ There is enormous variation in the rate of spinal fusion operations between countries and even regions within countries. ${ }^{29-31}$ Apparently, there is no true consensus on its indications, as was shown in a national survey among Dutch spine surgeons, which revealed a complete lack of uniformity in surgical decision making for CLBP. ${ }^{32}$

In a Cochrane review in $1999,{ }^{31}$ there was no evidence for the effectiveness of spinal fusion for CLBP. Nevertheless, there was a 220\% increase in spinal fusion surgery from 1990 to 2001 in the US, ${ }^{33}$ and Medicare expenses for lumbar fusion increased in 10 years from $\$ 75$ million to $\$ 482$ million, which was about $50 \%$ of the total costs for spine surgery in the US. ${ }^{31}$
The first randomized controlled trial ${ }^{34}$ showed a better clinical outcome for patients treated who underwent spinal fusion compared to patients who received standard conservative care. At longer follow-up, however, this beneficial effect was attenuated. ${ }^{35}$ Two more recent randomized controlled trials compared the outcome of spinal fusion to cognitive behavioral-based exercise therapy ${ }^{36}$ or an intensive rehabilitation program. ${ }^{37}$ The clinical results for surgery and the rehab programs at 2 years follow-up were equal. However, in the last trial, fusion had a higher complication rate and was less cost-effective than the structured rehab programs. ${ }^{38}$

Most spine surgeons do not consider complications or bad surgery, but bad patient selection, wrong diagnosis, and disproportionate expectations of patients to be the major factors for poor outcome in spinal surgery. ${ }^{39}$

The identification of subgroups of CLBP patients who truly benefit from spinal fusion would be helpful to improve the results of surgery. Unfortunately, the current routine diagnostic tools to select the right patient for lumbar fusion appear to be inadequate. History taking and physical examination can reveal psychosocial factors that lead to chronicity of pain, ${ }^{40,41}$ but there are no specific physical findings to predict the outcome of lumbar fusion. ${ }^{42}$ The association of CLBP with findings on imaging is weak. ${ }^{43}$ Degenerative signs on plain radiographs are not correlated with persisting symptoms of $\mathrm{CLBP}^{44}$ and magnetic resonance imaging (the imaging study of choice for the initial evaluation of patients with CLBP $)^{45}$ shows high false-positive rates of degenerative findings in asymptomatic people, especially in the elderly. ${ }^{11,46}$

\section{Provocative diskography as an aid in clinical decision making for pain intervention}

To identify those patients who will benefit from invasive treatment aimed at reducing presumed diskogenic pain, physicians may use provocative diskography (PD), which is assumed to predict the outcome of such treatment.

PD can be performed in an outpatient operating room with monitored anesthetic care under strict sterile conditions. The patients should receive instructions to fast for at least 6 hours before the procedure. Optimally, all diskographies are performed by a certified pain-interventional physician who performs the procedure frequently (preferably more than 50 annually). Thirty minutes before the intervention, prophylactic antibiotics ( $2 \mathrm{~g}$ cefazolin) can be administered intravenously.

Patients can be placed in the lateral decubitus or in the prone position on a radiolucent table (Figure 1). The skin in the low back and gluteal region is thoroughly disinfected with 


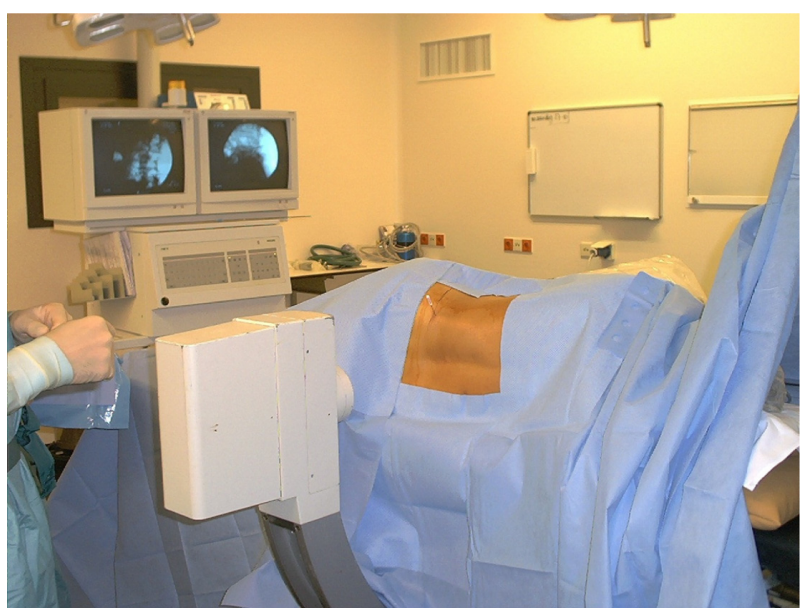

Figure I Provocative diskography is performed under sterile conditions and with biplanar fluoroscopic control. The intended disk space is injected with contrast agent to provoke usual back pain. In addition, the amount of degeneration can be visualized on radiographs or computerized tomography (CT).

chlorhexidine or iodine and draped. In the prone position, fluoroscopy is performed with the direction of the radiation beam positioned parallel to the subchondral plate of the lower vertebral end plate of the disk. In the disks above L5-S1, the fluoroscopy tube is rotated ipsilaterally until the lateral aspect of the superior articular process projects over the axial middle of the disk to be punctured. The target area for injection is the lateromedial side of the disk, just lateral to the edge of the superior articular process. At the L5-S1 level, the fluoroscopy tube is rotated until the lateral edge of the superior articular process of S1 projects approximately $25 \%$ over the posteroanterior distance of the vertebral body. ${ }^{47}$ The doubleneedle technique is advocated, in which an outer $18 \mathrm{~g} \times 3.5^{\prime \prime}$ $(8.89 \mathrm{~cm})$ introducer needle is advanced under fluoroscopic control to the margin of the disk (Figure 2). Next, an inner $22 \mathrm{~g} \times 6.0^{\prime \prime}$ needle is led through the outer needle and placed in the center of the disk. The double-needle technique is assumed to help in reducing the incidence of postdiskography diskitis, and allows the entering of the disk with needles of a small diameter.

When contrast dye is injected manually, generally highpressure peaks are achieved. It has been shown in asymptomatic subjects that in the case of provocation with high pressures above $50 \mathrm{psi}$, eventually all disks can be painful. ${ }^{48}$ Therefore, in order to avoid false-positive findings, PD should be carried out with a constant low flow and controlled continuous manometry by an automated system. For this, the diskography needle is connected to a pressure-controlled diskography device, which is calibrated for needle diameter,
A

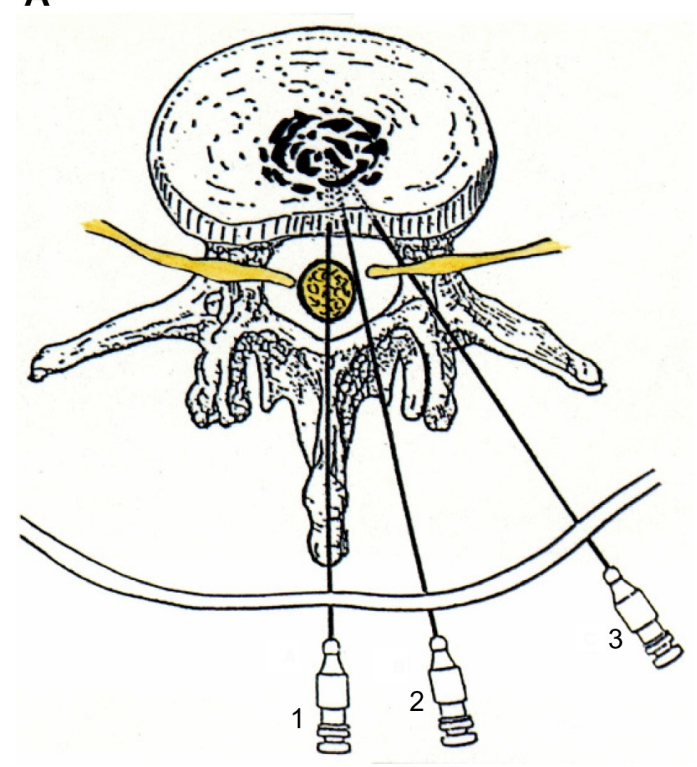

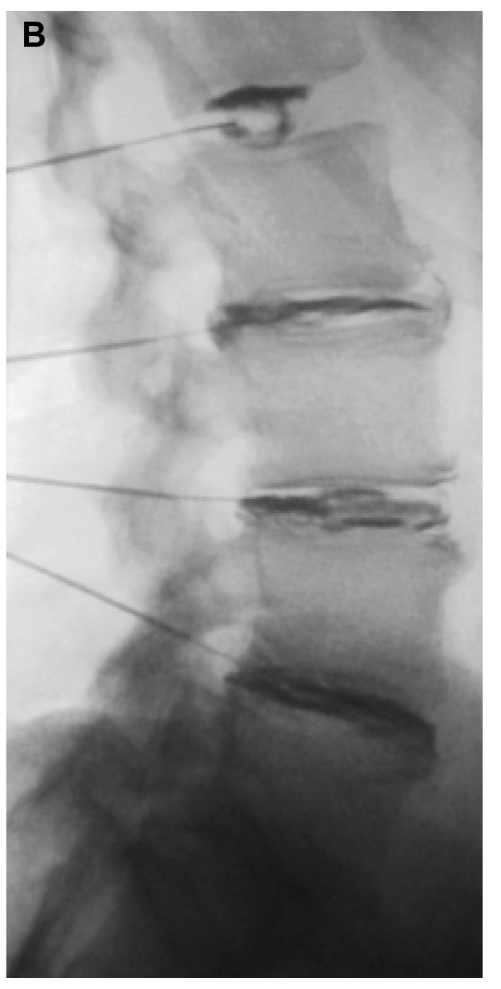

Figure 2 (A) A schematic axial view of the intervertebral disk with preferred location of the needle tip in the center. Needle-approach 3 is recommended as approaches I and 2 have a higher risk of leakage of cerebrospinal fluid with subsequent postprocedural headache. (B) A radiographic image of the lumbar spine after multilevel diskography showing in the upper disk an intact annulus fibrosus (contained contrast agent in the nucleus pulposus). The lower 3 disks show degeneration with annular tears as evidenced by leakage of contrast agent to the outer disk. 
needle length, contrast-dye viscosity, and fluid velocity. Preferred controlled-injection velocities are $0.05 \mathrm{~mL} / \mathrm{second}$ and $0.02 \mathrm{~mL} /$ second. $^{49}$

During injection, there should be continuous communication with the patient, and the patient's pain should be noted as rated on a numeric rating scale before and during the procedure. The moment the contrast dye first enters the nucleus pulposus, pressure is recorded as the opening pressure. The maximum accepted pressure above the opening pressure has been recommended to be $50 \mathrm{psi}^{50}$ and the maximum injection volume 3 $\mathrm{mL}$. Pain pressure level and volume level are recorded at the moment when the patient experiences concordant pain.

The degree of disk degeneration (Figure 2) can be classified according to the Dallas diskogram scale, ${ }^{51}$ in which grade 0 means no disruption, grades 1,2 , and 3 represent leakage of the contrast dye into the inner, middle, and outer layers of the annulus fibrosus, respectively, and in grade 4 there may be leakage outside the annulus (complete rupture). Vanharanta et $\mathrm{al}^{52}$ showed that grades $0-2$ are rarely painful and over $75 \%$ of grade 3 diskographies are painful.

Nevertheless, PD remains a controversial test, because it requires the patient's subjective pain response, and its reported accuracy for identifying diskogenic LBP has been reported as moderate to low. ${ }^{42}$

Of course, precise measurement of contrast volume and intradiskal pressure during injection will improve standardization and reproducibility of diskography, as the patient's pain response is related to the intensity of the provocative stimulus. ${ }^{49}$ Whether it will increase the diagnostic accuracy of PD, however, remains to be seen. The International Spine Intervention Society ${ }^{53}$ recommends four criteria at diskography in order to define diskogenic back pain: 1) provocation of the suspect disk induces concordant pain, 2) the pain is at least $7 / 10$ on a numeric rating scale, 3 ) the pain is provoked by less than 50 psi above opening pressure, and 4) provocation of at least one adjacent disk does not induce concordant pain. In a meta-analysis, pressure-controlled diskography with lowpressure criteria appeared to reduce the rate of false-positive disks to 0.06 in asymptomatic subjects. ${ }^{54}$ However, the review suffered from serious methodological limitations, and as there are no data on the sensitivity of PD for pain-interventional treatment, the clinical utility of these findings is low.

In a recent systematic review, diagnostic criteria of presumed diskogenic back pain were studied. ${ }^{55}$ In 36 studies, PD was used as the predominant technique. Additionally, analgesic diskography or "diskoblock" was used in one study. ${ }^{56}$ Of all included PD studies, only eight used pain scales to quantify the intensity of pain during disk injection. Six studies had measured intradiskal pressure during the procedure, and the absence of concordant pain at an adjacent level has been required in only 17 studies. As treatment for the suspected diskogenic back pain included spinal fusion, total disk replacement, disk denervation, and intradiskal injection techniques were used. Remarkably, provocation diskography was used in virtually all studies (95\%) that used minimally invasive pain intervention as treatment, whereas in surgical studies PD was used preoperatively in less than $60 \%$. As terminology and definitions used depended mainly on the treating physician's specialty, there appeared to be no clear definition of a painful disk and no reliable test to predict treatment outcome.

\section{The accuracy of PD in diagnosing diskogenic pain as a prognostic tool for successful spinal fusion}

PD is based on the assumption that pressurizing a symptomatic degenerated disk will incite nociceptive nerve endings, thus producing the pain that the patient recognizes as his or her daily-life back pain. Ideally, a gold standard confirming the presence or absence of diskogenic back pain should be available to determine diagnostic accuracy. However, surgical inspection of a degenerated disk cannot determine whether this disk is causing the patient's pain or not. The greatest problem for PD is the absence of a reliable reference standard.

Spinal fusion results have been used as a reference standard to determine the prognostic accuracy of PD. However, it should be stressed that neither spinal fusion nor lumbar disk replacement is a reliable and predictable effective treatment for diskogenic LBP. Although PD is used widely as a selection tool for operative treatment, very few studies have reported its prognostic accuracy for surgical outcome. In a recent systematic literature review, ${ }^{57}$ only four studies could be identified in which sensitivity, specificity, and predictive values of PD for spinal fusion outcome could actually be calculated, as in these studies negatively tested patients were also operated on and the risk of verification bias was thus avoided (Table 1). In particular, it appeared that the specificity of PD was very low (below 0.5), meaning that unnecessary surgery in patients who would not benefit from fusion could not be avoided, as the test did not identify these patients. It was therefore concluded that PD should not be used in clinical practice as a preoperative prognostic tool for the outcome of spinal fusion for LBP.

\section{Safety and long-term effects of PD}

Postdiskography diskitis, mainly caused by Staphylococcus aureus, is the most feared complication of PD. Although rare, diskitis can have serious consequences. The risk of 
postdiskography diskitis can be reduced by the use of intravenous or intradiskal antibiotic prophylaxis. ${ }^{58}$ Fraser et al showed that the use of a double-needle technique reduced the risk of postdiskographic diskitis from $2.7 \%$ to $0.7 \% .^{59}$ In a systematic literature review, Willems et al reported that in PD, without the use of prophylactic antibiotics, an overall diskitis incidence of $0.25 \%$ by patient and $0.094 \%$ by disk was found. ${ }^{60}$ In one of these selected papers, an unusually high incidence ( $1.90 \%$ by patient and $0.98 \%$ by disk) was reported..$^{59}$ This may have been caused by the fact that PD had been executed by less experienced diskographers. In the literature search, only one study of lumbar diskography with the use of prophylactic antibiotics, in which diskitis was specifically looked for, was selected.$^{58}$ In this series of 127 patients (337 disks), no case of diskitis was registered. However, given the aforementioned incidence of $0.25 \%$ by patient, to actually prove that additive antibiotics really prevent postdiskography diskitis, a randomized trial of 9,000 patients would be needed. It was concluded that the routine use of prophylactic antibiotics in PD is not indicated. PD should be carried out by experienced physicians who are meticulous with the two-needle technique and aseptic conditions. Nevertheless, international guidelines have recommended the routine use of antibiotic prophylaxis for $\mathrm{PD}$, in order to minimize the risk of postdiskography diskitis.

An alternative or addition to traditional PD is the technique known as diskoblock, which involves injecting the disk with an anesthetic agent instead of a contrast agent in an effort to eliminate instead of reproduce a patient's pain. This diskoblock technique was compared with PD by Ohtori et al. ${ }^{56}$ Forty-two patients planned for noninstrumented anterior lumbar interbody fusion with iliac crest autograft were randomized for a preoperative workup with either PD or diskoblock. Twelve patients were eliminated because of a lack of response with both techniques. No patient showed signs of pseudarthrosis at 2 years follow-up, based on plain radiographs and computed tomography scans. Those fused patients with positive diskoblock findings had a significantly better outcome in terms of pain and disability compared to those fused patients who had positive PD. This study provided level II evidence that the diskoblock technique might be a better predictor of clinical outcome after fusion surgery than traditional PD. A small sample size, lack of a power analysis, and the presence of verification bias (negatively tested patients did not receive fusion) limited this conclusion.

Recently, there has been concern that diagnostic disk injections may lead to iatrogenic injury of the disk, thus accelerating disk degeneration. Degeneration of an intervertebral disk due to a needle puncture has been demonstrated in animals. ${ }^{61}$

Carragee et al followed the progression of disk degeneration in magnetic resonance imaging studies in patients with and without a history of diskography. ${ }^{62}$ There was significantly more progression of disk degeneration and herniations in patients who had undergone PD.

\section{Conclusion}

There is still no clear definition of diskogenic LBP and no consensus on a generally agreed test, such as PD, to diagnose painful disk degeneration, and probably more importantly, to predict the outcome of therapy intended to reduce pain that is presumed to be diskogenic in nature.

PD is used in clinical practice to diagnose diskogenic LBP. It is advised to perform the procedure in a pressure-controlled way with a constant low flow, and optionally computed tomography imaging. The accuracy of PD in predicting the outcome of spinal fusion is low, with specificity less than 0.5 , meaning that most patients who will not benefit from fusion cannot be identified by the test. For pain-interventional treatment, there are not enough reliable data on the sensitivity of PD to predict treatment outcome in diskogenic back pain patients at all. Therefore, the test should not be recommended as a standalone test for treatment strategy in clinical practice.

Possibly, PD may have detrimental effects on the disk, causing progression of degeneration, although it is unknown whether this will be related to clinical symptoms. With regard to these possible adverse side effects, the risk-benefit ratio is uncertain, which should be stressed in the process of shared decision making with patients.

Table I Summary prognostic accuracy of provocative diskography for spinal fusion outcome

\begin{tabular}{|c|c|c|c|c|c|c|c|}
\hline Study & $\begin{array}{l}\text { Sample } \\
\text { size }\end{array}$ & Sensitivity & Specificity & $\begin{array}{l}\text { Positive } \\
\text { predictive value }\end{array}$ & $\begin{array}{l}\text { Negative } \\
\text { predictive value }\end{array}$ & $\begin{array}{l}\text { Positive LR } \\
(95 \% \mathrm{Cl})\end{array}$ & $\begin{array}{l}\text { Negative LR } \\
(95 \% \mathrm{Cl})\end{array}$ \\
\hline Colhoun et al ${ }^{63}$ & 168 & 0.88 & 0.48 & 0.88 & 0.48 & I.7I (I.2I-2.4I) & $0.24(0.13-0.43)$ \\
\hline Esses et $\mathrm{al}^{64}$ & 22 & 0.40 & 0.43 & 0.60 & 0.25 & $0.70(0.29-1.70)$ & $1.40(0.54-3.62)$ \\
\hline Gill and & 53 & 0.81 & 0.41 & 0.74 & 0.50 & $1.37(0.89-2.10)$ & $0.47(0.20-1.13)$ \\
\hline \multicolumn{8}{|l|}{ Blumenthal ${ }^{65}$} \\
\hline Willems et $\mathrm{al}^{66}$ & 82 & 0.73 & 0.27 & 0.45 & 0.55 & $0.99(0.76-1.30)$ & $1.01(0.49-2.08)$ \\
\hline
\end{tabular}

Abbreviations: $\mathrm{Cl}$, confidence interval; LR, likelihood ratio. 


\section{Disclosure}

The author reports no conflicts of interest in this work.

\section{References}

1. Walker BF. The prevalence of low back pain: a systematic review of the literature from 1966 to 1998. J Spinal Disord. 2000;13:205-217.

2. Slobbe LC, Kommer GJ, Smit JM, Groen J, Meerding WJ, Polder JJ. Kosten van Ziekten in Nederland 2003. Bilthoven, Netherlands: National Institute for Public Health and the Environment; 2006.

3. van Tulder MW, Koes BW, Bouter LM. A cost-of-illness study of back pain in The Netherlands. Pain. 1995;62:233-240.

4. Martin BI, Deyo, RA, Mirza SK, et al. Expenditures and health status among adults with back and neck problems. JAMA. 2008;299: 656-664.

5. Waddell G. 1987 Volvo award in clinical sciences. A new clinical model for the treatment of low-back pain. Spine (Phila Pa 1976). 1987;12: 632-644.

6. Deyo RA, Bass JE, Walsh NE, Schoenfeld LS, Ramamurthy S. Prognostic variability among chronic pain patients: implications for study design, interpretation, and reporting. Arch Phys Med Rehabil. 1988;69:174-178.

7. Modic MT, Masaryk TJ, Ross JS, Carter JR. Imaging of degenerative disk disease. Radiology. 1988;168:177-186.

8. Weishaupt D, Zanetti M, Hodler J, et al. Painful lumbar disk derangement: relevance of endplate abnormalities at MR imaging. Radiology. 2001;218:420-427.

9. Aprill C, Bogduk N. High-intensity zone: a diagnostic sign of painful lumbar disc on magnetic resonance imaging. Br J Radiol. 1992;65: 361-369.

10. Ito M, Incorvaia KM, Yu SF, Fredrickson BE, Yuan HA, Rosenbaum AE. Predictive signs of discogenic lumbar pain on magnetic resonance imaging with discography correlation. Spine (Phila Pa 1976). 1998;23:1252-1258; discussion 1259-1260.

11. Jensen MC, Brant-Zawadzki MN, Obuchowski N, Modic MT, Malkasian D, Ross JS. Magnetic resonance imaging of the lumbar spine in people without back pain. N Engl J Med. 1994;331:69-73.

12. Bigos SJ, Battie MC, Fisher LD. Methodology for evaluating predictive factors for the report of back injury. Spine (Phila Pa 1976). 1991;16: 669-670.

13. McIntosh G, Frank J, Hogg-Johnson S, Bombardier C, Hall H. Prognostic factors for time receiving workers' compensation benefits in a cohort of patients with low back pain. Spine (Phila Pa 1976). 2000;25:147-157.

14. Katz JN. Lumbar disc disorders and low-back pain: socioeconomic factors and consequences. J Bone Joint Surg Am. 2006;88 Suppl 2:21-24.

15. Waddell G. Low back pain: a twentieth century health care enigma. Spine. 1996;21:2820-2825.

16. Pincus T, Burton AK, Vogel S, Field AP. A systematic review of psychological factors as predictors of chronicity/disability in prospective cohorts of low back pain. Spine. 2002;27:E109-E120.

17. Battié MC, Videman T, Levälahti E, Gill K, Kaprio J. Genetic and environmental effects on disc degeneration by phenotype and spinal level: a multivariate twin study. Spine. 2008;33:2801-2808.

18. Cheung KM, Chan D, Karppinen J, et al. Association of the Taq I allele in vitamin $\mathrm{D}$ receptor with degenerative disc disease and disc bulge in a Chinese population. Spine. 2006;31:1143-1148.

19. Coppes MH, Marani E, Thomeer RT, Groen GJ. Innervation of "painful" lumbar discs. Spine (Phila Pa 1976). 1997;22:2342-2349; discussion 2349-2350.

20. Peng B, Wu W, Hou S, Li P, Zhang C, Yang Y. The pathogenesis of discogenic low back pain. J Bone Joint Surg Br. 2005;87:62-67.

21. Burke JG, Watson RW, McCormack D, Dowling FE, Walsh MG, Fitzpatrick JM. Intervertebral discs which cause low back pain secrete high levels of proinflammatory mediators. J Bone Joint Surg Br. 2002; 84:196-201.
22. Kang JD, Stefanovic-Racic M, McIntyre LA, Georgescu HI, Evans CH. Toward a biochemical understanding of human intervertebral disc degeneration and herniation. Contributions of nitric oxide, interleukins, prostaglandin E2, and matrix metalloproteinases. Spine. 1997;22: 1065-1073.

23. Kang JD, Georgescu HI, McIntyre-Larkin L, Stefanovic-Racic M, Donaldson WF 3rd, Evans CH. Herniated lumbar intervertebral discs spontaneously produce matrix metalloproteinases, nitric oxide, interleukin-6, and prostaglandin E2. Spine (Phila Pa 1976). 1996;21: 271-277.

24. Franson RC, Saal JS, Saal JA. Human disc phospholipase A2 is inflammatory. Spine (Phila Pa 1976). 1992;17:S129-S132.

25. Hadra BE. Wiring of the spinous process in injury and Pott's disease. Trans Am Orthop Assoc. 1891;4:206-210.

26. Krismer M. Fusion of the lumbar spine. A consideration of the indications. J Bone Joint Surg Br. 2002;84:783-794.

27. Deyo RA, Nachemson A, Mirza SK. Spinal-fusion surgery - the case for restraint. $N$ Engl J Med. 2004;350:722-726.

28. Carragee EJ. Clinical practice. Persistent low back pain. $N$ Engl J Med. 2005;352:1891-1898.

29. Katz JN. Lumbar spinal fusion. Surgical rates, costs, and complications. Spine. 1995;20:78S-83S.

30. Weinstein JN, Lurie JD, Olson PR, Bronner KK, Fisher ES. United States' trends and regional variations in lumbar spine surgery: 1992-2003. Spine. 2006;31:2707-2714.

31. Gibson JN, Grant IC, Waddell G. The Cochrane review of surgery for lumbar disc prolapse and degenerative lumbar spondylosis. Spine. 1999;24:1820-1832.

32. Willems P, de Bie R, Öner C, Castelein R, de Kleuver M. Clinical decision making in spinal fusion for chronic low back pain. Results of a nationwide survey among spine surgeons. BMJ Open. 2011;1:e00391.

33. Deyo RA, Gray DT, Kreuter W, Mirza S, Martin BI. United States trends in lumbar fusion surgery for degenerative conditions. Spine (Phila Pa 1976). 2005;30:1441-1445; discussion 1446-1447.

34. Fritzell P, Hägg O, Wessberg P, Nordwall A. 2001 Volvo Award Winner in Clinical Studies: Lumbar fusion versus nonsurgical treatment for chronic low back pain: a multicenter randomized controlled trial from the Swedish Lumbar Spine Study Group. Spine. 2001;26:2521-2532; discussion 2532-254.

35. Fritzell P, Hägg O, Jonsson D, Nordwall A. Cost-effectiveness of lumbar fusion and nonsurgical treatment for chronic low back pain in the Swedish Lumbar Spine Study: a multicenter, randomized, controlled trial from the Swedish Lumbar Spine Study Group. Spine. 2004;29:421-434; discussion Z3.

36. Brox JI, Sørensen R, Friis A, et al. Randomized clinical trial of lumbar instrumented fusion and cognitive intervention and exercises in patients with chronic low back pain and disc degeneration. Spine. 2003;28: 1913-1921.

37. Fairbank J, Frost H, Wilson-MacDonald J, Yu LM, Barker K, Collins R. Randomized controlled trial to compare surgical stabilization of the lumbar spine with an intensive rehabilitation programme for patients with chronic low back pain: the MRC spine stabilization trial. $B M J$. 2005;330:1233.

38. Rivero-Arias O, Campbell H, Gray A, Fairbank J, Frost H, WilsonMacDonald J. Surgical stabilization of the spine compared with a programme of intensive rehabilitation for the management of patients with chronic low back pain: cost utility analysis based on a randomized controlled trial. BMJ. 2005;330:1239.

39. Haefeli M, Elfering A, Aebi M, et al. What comprises a good outcome in spinal surgery? A preliminary survey among spine surgeons of the SSE and European spine patients. Eur Spine J. 2008;17:104-116.

40. Deyo RA, Rainville J, Kent DL. What can the history and physical examination tell us about low back pain? JAMA. 1992;268:760-765.

41. Nelson MA, Allen P, Clamp SE, de Dombal FT. Reliability and reproducibility of clinical findings in low-back pain. Spine (Phila Pa 1976). 1979;4:97-101. 
42. Carragee EJ. Clinical practice. Persistent low back pain. $N$ Engl J Med. 2005;352:1891-1898.

43. van Tulder MW, Assendelft WJ, Koes BW, Bouter LM. Spinal radiographic findings and nonspecific low back pain. A systematic review of observational studies. Spine. 1997;22:427-434.

44. Kumar MN, Jacquot F, Hall H. Long-term follow-up of functional outcomes and radiographic changes at adjacent levels following lumbar spine fusion for degenerative disc disease. Eur Spine J. 2001;10: 309-313.

45. Resnick DK, Choudhri TF, Dailey AT, et al. Guidelines for the performance of fusion procedures for degenerative disease of the lumbar spine. Part 2: assessment of functional outcome. J Neurosurg Spine. 2005;2:639-646.

46. Boden SD, McCowin PR, Davis DO, Dina TS, Mark AS, Wiesel S. Abnormal magnetic-resonance scans of the cervical spine in asymptomatic subjects. A prospective investigation. J Bone Joint Surg Am. 1990;72:1178-1184.

47. Kallewaard JW, Terheggen MA, Groen GJ, et al. Evidence based medicine: discogenic low back pain. In: Van Zundert J, Huygen F, Patijn J, van Kleef M, editors. Praktische Richtlijnen Anesthesiologische Pijnbestrijding: Gebaseerd op Klinische Diagnosen. Maastricht, Netherlands: NVA; 2009:145-161.

48. O’Neill C, Kurgansky M. Subgroups of positive discs on discography. Spine. 2004;29:2134-2139.

49. Seo KS, Derby R, Date ES, Lee SH, Kim BJ, Lee CH. In vitro measurement of pressure differences using manometry at various injection speeds during discography. Spine J. 2007;7:68-73.

50. Derby R, Howard MW, Grant JM, Lettice JJ, Van Pethegem PK, Ryan DP. The ability of pressure-controlled discography to predict surgical and nonsurgical outcomes. Spine. 1999;24:364-371.

51. Sachs BL, Vanharanta H, Spivey MA, et al. Dallas discogram description. A new classification of CT/discography in low-back disorders. Spine. 1987;12:287-294.

52. Vanharanta H, Sachs BL, Spivey MA, et al. The relationship of pain provocation to lumbar disc deterioration as seen by CT/discography. Spine. 1987;12:295-298.

53. Bogduk N. Provocation discography: lumbar disc stimulation. In: Bogduk N, editor. Practice Guidelines for Spinal Diagnostic and Treatment Procedures. San Francisco: International Spine Intervention Society; 2004:20-46.
54. Wolfer LR, Derby R, Lee JE, Lee SH. Systematic review of lumbar provocation discography in asymptomatic subjects with a meta-analysis of false-positive rates. Pain Physician. 2008;11:513-538.

55. Malik KM, Cohen SP, Walega DR, Benzon HT. Diagnostic criteria and treatment of discogenic pain: a systematic review of recent clinical literature. Spine J. 2013;13:1675-1689.

56. Ohtori S, Kinoshita T, Yamashita M, et al. Results of surgery for discogenic low back pain: a randomized study using discography versus discoblock for diagnosis. Spine (Phila Pa 1976). 2009;34:1345-1348.

57. Willems PC, Staal JB, Walenkamp GH, de Bie RA. Spinal fusion for chronic low back pain: systematic review on the accuracy of tests for patient selection. Spine J. 2013;13:99-109.

58. Osti OL, Fraser RD, Vernon-Roberts B. Discitis after discography. The role of prophylactic antibiotics. J Bone Joint Surg Br. 1990;72: 271-274.

59. Fraser RD, Osti OL, Vernon-Roberts B. Discitis after discography. J Bone Joint Surg Br. 1987;69:26-35.

60. Willems PC, Jacobs WC, Duinkerke ES, De Kleuver M. Lumbar discography: should we use prophylactic antibiotics? J Spinal Disord Tech. 2004;17:243-247.

61. Sobajima S, Kompel JF, Kim JS, et al. A slowly progressive and reproducible animal model of intervertebral disc degeneration characterized by MRI, X-ray, and histology. Spine (Phila Pa 1976). 2005;30: $15-24$.

62. Carragee EJ, Don AS, Hurwitz EL, Cuellar JM, Carrino JA, Herzog R. 2009 ISSLS Prize Winner: Does discography cause accelerated progression of degeneration changes in the lumbar disc: a ten-year matched cohort study. Spine (Phila Pa 1976). 2009;34:2338-2345.

63. Colhoun E, McCall IW, Williams L, Cassar Pullicino VN. Provocation discography as a guide to planning operations on the spine. J Bone Joint Surg Br. 1988;70:267-271.

64. Esses SI, Botsford DJ, Kostuik JP. The role of external spinal skeletal fixation in the assessment of low-back disorders. Spine (Phila PA 1976). 1989;14(6):594-601.

65. Gill K, Blumenthal SL. Functional results after anterior lumbar fusion at L5-S1 in patients with normal and abnormal MRI scans. Spine. 1992;17(8):940-942.

66. Willems PC, Elmans L, Anderson PG, van der Schaaf DB, de Kleuver M. Provocative discography and lumbar fusion: is preoperative assessment of adjacent discs useful? Spine (Phila PA 1976). 2007;32(10):1094-1099.
Journal of Pain Research

\section{Publish your work in this journal}

The Journal of Pain Research is an international, peer-reviewed, open access, online journal that welcomes laboratory and clinical findings in the fields of pain research and the prevention and management of pain. Original research, reviews, symposium reports, hypothesis formation and commentaries are all considered for publication.

\section{Dovepress}

The manuscript management system is completely online and includes a very quick and fair peer-review system, which is all easy to use. Visit http://www.dovepress.com/testimonials.php to read real quotes from published authors. 